\title{
Improving health literacy - bridging the gap between newcomer populations and quality health care
}

\author{
Richard Yu, Anamika Mishra
}

\begin{abstract}
Health literacy is the ability to obtain and utilize health information in order to advocate for one's health. It is paramount to a recent immigrant's successful integration into the Canadian healthcare system and their maintenance of health in the long term. Despite its importance, $60 \%$ of nativeborn Canadians and an even higher proportion of immigrants indicate that they are not health literate. In this article, we focus on the importance of health literacy in an immigrant population and current barriers they may face in accessing health care. We discuss current shortcomings within the healthcare system in terms of improving health literacy for newcomers and explore strategies currently used in the United States and Canada. Based on our review of the literature, it is clear that promoting health literacy is a multi-dimensional challenge which requires the synthesis of many strategies, including clear written and oral communication, use of multimedia tools, cultural sensitivity, participatory teaching, community resources, and availability of diverse care providers who can relate to newcomers linguistically and culturally.
\end{abstract}

\section{INTRODUCTION}

Health literacy has become an increasingly important concept in the provision of quality healthcare for newcomer populations. As Canada increases its admission of immigrant populations, with over 290,000 new permanent residents in 2016 and with plans to bring in over 340,000 by 2020 , the importance of providing and maintaining quality health care for these disadvantaged groups is becoming more apparent. ${ }^{1}$ The heterogenous cultural and educational backgrounds of immigrants can often lead to challenges in promoting health literacy.

Currently, Canada has an extensive medical screening system to assess the health of newcomers prior to admission into the country. This entails screening for infectious diseases such as Hepatitis B and tuberculosis. ${ }^{2}$ Such a system is important for maintaining public safety for Canadians, mitigating financial burdens within the healthcare system, and allowing for early connection between newcomers and the Canadian healthcare system. ${ }^{2}$ This rigorous positive selection process has led to the phenomenon of the "healthy immigrant effect", whereby the average health of immigrants, when entering a new country, is higher than that of the general population. ${ }^{3}$ However, despite being healthier initially, their health rapidly declines over time, indicating a lack in successful implementation of current policies for maintaining their health. ${ }^{3}$ Maintenance of health is important for their successful immigration and integration into Canadian society.

Health care professionals (HCP) have an important role in bridging the gap between newcomers and quality health care by providing education on health literacy. Here, we examine the importance of health literacy within newcomer populations and we discuss ongoing efforts to improve, in order to provide recommendations that may help address some of the current shortcomings within the Canadian health care system.

\section{IMPORTANCE OF HEALTH LITERACY}

Health literacy is defined as the patient's ability to effectively receive, understand and utilize health information to advocate for one's own health. ${ }^{4}$ It is further characterized by its multi-dimensional communicative nature, which involves looking at all aspects of an individual's life and coordinating care with multiple parties. ${ }^{4}$ A report by the Canadian Council on Learning, which surveyed 23,000 Canadians, showed that $60 \%$ of adults lack the capacity to understand and act on health information. ${ }^{5}$ Importantly, health literacy has been linked directly to health outcomes. Individuals with lower health literacy skills were 1.5 to 3 times more likely to experience negative health outcomes. ${ }^{6}$ This relationship is present when accounting for age, sex, ethnicity, immigration and aboriginal status, indicating the potential benefit of improving health literacy at the population level. ${ }^{7}$ Other important outcomes of low literacy include decreased income and diminished community engagement, which are important socioeconomic factors that influence health indirectly. ${ }^{6}$

The significance of health literacy is especially impactful for recent immigrants, as another study showed that $60 \%$ of immigrants fell below the literary competency level required for coping with the demands of everyday life. ${ }^{8}$ This would make understanding health information particularly difficult, especially in the context of settling in a new country. Importantly, low health literacy leads to poor self-management of health and poor implementation of preventative strategies which exacerbates the decline in newcomer health. Recent studies have shown newcomers in Canada were less likely to access mental health services and cervical cancer screenings. ${ }^{910}$ This illustrates the fact that recent immigrants typically have less knowledge of the healthcare system and the services provided, and thus, are less able to advocate for their own health.

This is compounded by the fact that immigrants must accommodate different cultural views of science and health. ${ }^{11}$ 
For example, physicians have cited difficulty in communicating ideas of "risky behavior" to those who are less literate. ${ }^{11}$ In some cultures, consumption of tobacco is not viewed in the same lens as a major risk factor for diseases. Other cultures prefer traditional or alternative medicines to treat diseases and may prefer to forego evidence-based treatments. ${ }^{11}$ These discrepancies in cultural perception of health contributes to both decreased health literacy and rapid decline in newcomer health.

\section{CURRENT BARRIERS}

There are currently many barriers that impact the health and overall quality of life for newcomers at the individual and systemic levels. ${ }^{12}$ Newcomers often feel stigmatized for not being able to fluently converse in English or French. This stigma, combined with suspicion for authority and feelings of cultural isolation, makes it less likely for newcomers to seek out and trust healthcare providers. ${ }^{12}$ An incomplete understanding of the language may also lead to misunderstandings in relation to tasks such as instructions for taking medications. ${ }^{12}$ This language barrier in turn feeds back and fuels poor health literacy, as healthcare workers are not able to explain medical concepts to immigrants and immigrants feel that their health care needs are not being met.

Systemically, health literacy relates to broader aspects within society such as education and discrimination. For example, in Ontario, between 2000 and 2007, there was a 29\% increase in English as a Second Language (ESL) students within elementary schools, but a decline in ESL teachers by $23 \%$. This meant that the general literacy skills of many newcomer children were not developing enough to be able to understand medical information relevant to their health. ${ }^{12}$

Furthermore, a recent study which surveyed approximately 7700 immigrants showed that discrimination towards immigrants leads to a decline in self-reported health status and overall worse health outcomes. ${ }^{13}$

\section{CURRENT STRATEGIES AND MAINTAINING GOOD PRACTICE}

There are many notable Canadian initiatives whose goals are to improve health literacy among Canadians, such as the National Literacy and Health Program (NLHP), Health Canada's Community Action Program for Children (CAPC) and the Fédération canadienne pour l'alphabétisation en français (FCAF). ${ }^{14-}$ ${ }^{16}$ However, it is important to note that none of these initiatives have a focus on improving health literacy with recent immigrants in Canada. Current strategies employed in the United States have seen a degree of success, such as the Students Helping in Naturalization of Elders (project SHINE). The teaching method utilized by project SHINE is participatory in nature, meaning that lessons are adapted to the participants by catering towards specific topics of interest, such as communication in a doctor's office, medicine management, and healthy aging. ${ }^{17}$ Another resource developed by Ottawa Public Health, called the Health Skills Health Smart (HSHS) Project, is similar in scope to project SHINE, although it has been limited in its operation scale due to fiscal constraints compounded by growing demand in recent years. ${ }^{18}$
In the clinic, HCP who are involved in the care of recent immigrants should be mindful of communication with them. A previous Canadian study identified three major domains for good health literacy practices: 1) clear and simplified writing, 2) clear oral communication, utilizing translators when applicable, and 3) use of visual tools and other multimedia formats such as video. ${ }^{19}$ Currently, these are the most common strategies employed, and maintenance of these strategies is important as it has been shown that overall literacy improves. However, they do not appear to change healthrelated behaviors; thus, further intervention is necessary. ${ }^{19}$

Emerging literature suggests that sensitivity training for physicians may be helpful. Immigration to a new country is a major and often dramatic environmental shift which many Canadian physicians have not experienced themselves. ${ }^{12}$ This is supported by the fact that the most promising health literacy outcomes are tied to having a HCP who is linguistically and/or culturally competent for the community involved. ${ }^{20}$ This highlights the importance of having culturally diverse HCP, since they can culturally relate to newcomers to establish a relationship of trust. They may also be more knowledgeable about community resources, such as religious leaders or cultural support networks, that may help the newcomers to integrate into the new environment. ${ }^{21}$ Despite the limited number of initiatives within Canada that help promote health literacy, physicians still have a broad range of strategies available to help immigrants adapt to Canada, break down barriers, and improve their health literacy.

\section{CONCLUSION}

In conclusion, health literacy is an increasingly important consideration in health promotion for recent immigrants. Most immigrants arrive in Canada generally healthier than the native population; however, due to lower health literacy levels, they are unable to advocate for their own health needs, leading to a decline in overall health. This is in part due to cultural differences in perceptions of health, as well as many barriers at the individual and systemic level that affect how these populations interact with the health care system. Current Canadian initiatives to improve health literacy do not have a focus on recent immigrants. Initiatives utilizing participatory teaching, such as project SHINE and HSHS, may be a source of guidance in developing initiatives within Canada. Physicians can promote health literacy for newcomers in their clinic by providing simple and clear written and oral communication and by being culturally sensitive to the immigration process. The importance of culturally relatable physicians has been noted as they seem to have a more intimate understanding of the culture, language, and community resources. Overall, by being mindful of the developing strategies and resources available, physicians can reduce inequities in the healthcare system and begin improving health literacy within newcomer populations in order to improve their health in the long term. 


\section{REFERENCES}

1. Government of Canada. Annual report to Parliament on immigration [Internet]. Ottawa (ON): Government of Canada; 2017 [cited 2018 Nov 30]. Available from: https://www.canada.ca/en/immigrationrefugees-citizenship/corporate/publications-manuals/annual-reportparliament-immigration-2017.html\#secl_2

2. Immigration, Refugees and Citizenship Canada [Internet]. Ottawa (ON): Immigration, Refugees and Citizenship Canada. Evaluation of the health screening and notification program; 2015 [cited 2018 Nov 30]. Available from: https://www.canada.ca/content/dam/ircc/ migration/ircc/english/pdf/pub/e8-2013-hsn-english.pdf

3. Vang Z, Sigouin J, Flenon A, et al. The healthy immigrant effect in Canada: a systematic review. Population change and lifecourse strategic knowledge cluster discussion paper series [Internet]. 2015 [cited 2018 Nov 30];3(1):4. Available from: http://ir.lib.uwo.ca/pclc/ vol3/issl/4

4. Rootman I, Frankish J, Kaszap M. Health literacy: a new frontier, in health promotion in Canada. In: O’Neill M, Dupéré S, Pederson A et al, editors. Critical perspectives. Canadian Scholars' Press; 2007. 61-74.

5. Simich L. Health literacy and immigrant populations [Internet]. Ottawa (ON): Public Health Agency of Canada; 2009 [cited 2018 Nov 3]. Available from: http://www.metropolis.net/pdfs/health_literacy= policy_brief_jun15_e.pdf

6. DeWalt DA, Berkman N, Sheridan S, et al. Literacy and health outcomes: a systematic review of the literature. J Gen Intern Med. 2004;19(12):1228-39. https://doi.org/10.1111/j.1525-1497.2004.40153.x

7. Canadian Council on Learning. Health literacy in Canada: a healthy understanding [Internet]. Ottawa: Canadian Council on Learning; 2008 [cited 2018 Nov 30]. Available from: http://www.en.copian.ca/ library/research/ccl/health/health.pdf

8. Canadian Public Health Association. Increasing understanding of the impact of low health literacy on chronic disease prevention and control: final report. Ottawa: Canadian Publich Health Association; 2006 [cited 2018 Nov 30]. Available from: https://www.cpha.ca/sites/ default/files/assets/annual-reports/2006_ar_e.pdf

9. Durbin A, Moineddin R, Lin E, et al. Mental health service use by recent immigrants from different world regions and by nonimmigrants in Ontario, Canada: a cross-sectional study. BMC Health Serv Res. 2015;15:336. https://doi.org/10.1186/s12913-015-0995-9

10. McDonald JT, Kennedy S. Cervical cancer screening by immigrant and minority women in Canada. J Immigr Minor Health. 2007;9(4):32334. https://doi.org/10.1007/s10903-007-9046-x

11. Zanchetta M, Poureslami I. Health literacy within the reality of immigrants' culture and Language. Can J Public Health. 2006;97 Suppl 2:S26-30.

12. Rootman I, Gordon-El-Bihbety D. A vision for a health literate Canada - report of the Expert Panel on Health Literacy [Internet]. Canadian Public Health Association; 2008 [cited 2018 Nov 30]. Available from: https://www.cpha.ca/sites/default/files/uploads/resources/healthlit/ report_e.pdf

13. De Maio FG, Kemp E. The deterioration of health status among immigrants to Canada. Glob Public Health. 2010;5(5):462-78. https:// doi.org/10.1080/17441690902942480

14. Wilson R. 2004. Retrospective evaluation of the National Literacy and Health Program [Internet]. Unpublished report. Ottawa: Canadian Public Health Association; 2008 [cited 2018 Nov 30]. Available from: http://en.copian.ca/library/research/evalu/evaluation.pdf

15. Government of Canada. Community Action Program for Children (CAPC) evaluation [Internet]. Ottawa (ON): Government of Canada;
2011 [cited 2018 Nov 30]. Available from: https://www.canada.ca/en/ public-health/services/health-promotion/childhood-adolescence/ programs-initiatives/community-action-program-children-capc/ community-action-program-children-capc-evaluation.html

16. Fédération canadienne pour l'alphabétisation en français. Annual report 2004-2006 [Internet]. Ottawa (ON): Fédération canadienne pour l'alphabétisation en français. 2005 [cited 2018 Nov 30]. Available from: http://www.resdac.net/documentation/pdf/rapportsannuels/ highlights2004-2006.pdf

17. Wrigley HS. Dimensions of immigrant integration and civic engagement: Issues and Exemplary programs. New Dir Adult Cont Educ. 2012;135:25-32. https://doi.org/10.1002/ace.20023

18. Ottawa Local Immigration Partnership. [Internet]. Ottawa (ON): Ottawa Local Immigration Partnership. Health and wellbeing. 2015 [cited 2018 Nov 30]. Available from: http://olip-plio.ca/wp-content/ uploads $/ 2015 / 06 /$ health-and-wellbeing-chapter-FINAL.pdf

19. Shohet L, Renaud L. Critical analysis on best practices in health literacy. Can J Public Health. 2006;97 Suppl 2:S10-3.

20. Elder JP, Ayala GX, Campbell NR, et al. Interpersonal and print nutrition communication for a Spanish-dominant Latino population: Secretos de la Buena Vida. Health Psychol. 2005;24(1):49-57. https:// doi.org/10.1037/0278-6133.24.1.49 